\title{
SOLID ACID CATALYSTS IN HETEROGENEOUS n-ALKANES HYDROISOMERISATION FOR INCREASING OCTANE NUMBER OF GASOLINE
}

*GALADIMA, A., ANDERSON, J. A. \& WELLS, R. P. K.

Surface chemistry and catalysis Research Group

University of Aberdeen, AB24 3UE, Aberdeen, UK. *agaladima@abdn.ac.uk

\begin{abstract}
As the current global environmental concerns have prompted regulations to reduce the level of aromatic compounds, particularly benzene and its derivatives in gasoline, hydroisomerisation of $n$-alkanes is becoming a major alternative for enhancing octane number. Series of solid acid catalysts comprising of Freidel crafts, zirconias, $\mathrm{MoO}_{3}$-based (MOB), chlorinated $\mathrm{Al}_{2} \mathrm{O}_{3}$, heteropoly acids and bifunctional zeolite based catalysts have been tested in this respect. This paper reviewed important studies conducted on these catalysts with the aim of identifying areas requiring further investigation(s). Freidel craft catalysts are currently abandoned due to corrosion and disposal problems. MOB and heteropoly acids have good resistance to nitrogen and sulphur in a reaction stream but have poor thermal stability, difficult to regenerate and with mechanism their action only partly resolved. Bifunctional zeolites on the other hand are increasingly becoming promising catalysts due to resulting high acidity, activity and easy regeneration properties. Both solid and gaseous acid modifiers could similarly modify their textural characteristics. The activities of all catalysts could under uncontrolled conditions lead to side reactions such as cracking, aromatisation and dehydrogenation.
\end{abstract}

Keywords; Solid acids, n-alkanes, hydroisomerisation catalysts, gasoline, octane number.

\section{INTRODUCTION}

The isomerisation of $\mathrm{n}$-alkanes in gasoline to their corresponding branched isomers for increasing its octane number is increasingly becoming an issue of special interest in the petroleum industry. This critically relates to the environmental desire for mitigating challenges associated with the use of Lead and/or high aromatics and oleifins content (Serra et al., 2003) as well as economic inconsistencies. Thus, the isomerisation method serves as a better alternative that could be used to produce high performance gasoline suitable for compliance with environmental policies. Some products generated from the isomerisation could also be used for other industrial applications as reported by Ono (2003) that an iso-butane could be dehydrogenated and converted to methyl t-butyl ether (MTBE), which has also found application as gasoline additive for raising octane number due to its oxygenation property and as a low explosive solvent. The isomerisation option gaining attention globally today is the "hydroisomerisation" carried out in the presence of solid acid catalysts.

Hydroisomerisation of gasoline fractions containing n-pentane, nhexane and n-heptane over 12 Membered Ring (MR) zeolites (mordenite MOR and SSZ-24) with different pore diameters had been reported (Chica \& Coma, 1999). The reactions were monitored in a stainless steel fixed bed continuous reactor with 15mol mol-1 Hydrogen/hydrocarbon ratio, 20 bar total pressure and temperatures of $240-380{ }^{\circ} \mathrm{C}$. Among these, the catalyst SSZ-24 with larger pore diameter shows better selectivity to branched products and acidity than the mordenite regardless of silicaalumina (Si/Al) ratio of the mordenite employed. However, the selectivity of the reactants followed the order pentane $<$ hexane $<$ heptane for all the catalysts.

Eswaramoorthi et al., (2004) hydrothermally synthesized mesoporous Al-MCM-41 and zirconium containing Al-MCM-41 with a Si/Zr ratio of 200, 100 and 50 . After structural confirmation by XRD, the catalysts were tested in the isomerisation of $\mathrm{C}_{6}$ to $\mathrm{C}_{7} \mathrm{n}$ alkanes at temperatures between $225-375^{\circ} \mathrm{C}$. Both mono- and dimethyl isomers were obtained especially when the catalysts were loaded with Pt metal, accounting for a skeletal arrangement in both $n$-hexane and $n$-heptane carbon chain. It was similarly found that the introduction of $\mathrm{Zr}$ in Al-MCM-41 framework significantly promotes the conversion as well as isomerisation selectivity in both $n$-hexane and $n$-heptane at all the temperatures studied. The AlMCM-41 with a Si/Zr ratio of 50 shows a maximum conversion of $46.3 \mathrm{wt} \%$ with isomerisation selectivity of $88.1 \%$ at $375{ }^{\circ} \mathrm{C}$ compared to maximum $n$-hexane conversion of $25.8 \mathrm{wt} . \%$ with 83.4\% isomerisation selectivity obtained with the Zr-free Al-MCM41 catalysts. In general, all the catalysts show higher conversions at $375{ }^{\circ} \mathrm{C}$ but with little concentrations of cracked and aromatised products.

Both, Karthikeyan et al., (2008) and Martins et al., (2008) reported the hydroisomerisation of $n$-hexane and $n$-decane using bifunctional metallic catalysts (Pt and/or Ni loaded over solid acids). The studies do not only addressed the role of metallic component but also the overall catalysts activity and selectivity. The isomerisation activities of $\mathrm{Ni}$ loaded and $\mathrm{Ni}$ free $\mathrm{Pd} / \mathrm{H}$ - 
mordenite catalysts explored indicate that addition of $\mathrm{Ni}$ (up to $0.2 \mathrm{wt} . \%$ ) over $0.1 \mathrm{wt} . \% \mathrm{Pd} / \mathrm{H}$-mordenite, increased the $n$-decane conversion and isomerisation selectivity at the temperature range of $200-450{ }^{\circ} \mathrm{C}$ employed. On the other hand, Martins et al., (2008) shows that the 1.0 wt.\% of Pt was introduced to the MCM-22 zeolite catalyst by ion exchange with $\mathrm{Pt}\left(\mathrm{NH}_{3}\right)_{4}{ }^{2+}$, incipient wetness impregnation with $\mathrm{PtCl}_{6} \mathrm{H}_{2}$ and mechanical mixture with $\mathrm{Pt} / \mathrm{Al}_{2} \mathrm{O}_{3}$ and the Pt dispersion over the catalyst was determined by transmission electron microscopy. Pt forms an outer surface layer when impregnated but exists within the inner micropores from the ion exchange preparation method. Overall, the high temperature influence of the metal indicates significant increase in the activity and selectivity for the isomerisation of $n$-hexane.

Generally, the main reaction path way for $n$-alkanes isomerisation over solid acids involved the formation of carbenium ion resulting from the reaction of $\mathrm{H}^{+}$with $\mathrm{n}$-alkane, which isomerises to an isocarbenium ion and later yield corresponding iso-alkane by hydride transfer (Ono, 2003). In the later step a tertiary carbenium ion maybe converted to a secondary carbenium ion and this thermodynamically requires energy.

$n-\mathrm{RH}+\mathrm{H}^{+} \rightleftharpoons \mathrm{n}-\mathrm{R}^{+}+\mathrm{H}_{2}, \quad \mathrm{n}-\mathrm{R}^{+} \rightleftharpoons \mathrm{iso}^{+}, \quad$ iso $\mathrm{R}^{+}+\mathrm{n}-\mathrm{RH} \rightleftharpoons \mathrm{n}-\mathrm{R}^{++}$ iso $\mathrm{RH}$

Consequent to the development of bifunctional catalysts, it is now accepted that the hydroisomerisation obeys three elementary steps mechanism. The initial step involved the dehydrogenation of the nalkane to a corresponding n-alkene, which isomerises in the second step and finally hydrogenates to the desired iso-alkane. Although this mechanism had been established, there are series of unresolved issues to be addressed. This overview discussed a critical survey of the catalysts employed for alkanes isomerisation, mechanism involved and the areas requiring further investigations.

A: CHLORIDE CATALYSTS: The chloride catalysts otherwise called Friedel crafts or Lewis acid catalysts like $\mathrm{AlCl}_{3}, \mathrm{SbCl}_{3}, \mathrm{FeCl}_{3}$ e.t.c. had been used as isomerisation catalysts during the earlier industrial time (Ono, 2003). The advantage offered by these catalysts is that presence of small quantities of water in the nalkane feedstock can lead to the formation of strongly polarised hydroxyl group (O-----H), which have consequent effect of increasing the isomerisation rate. Similarly, they show strong activity even at lower temperature of $300-390 \mathrm{~K}$. This is chemically favourable because the equilibrium position shifts to the right, yielding more branched isomers at shorter reaction time.

The order of acid strength of $\mathrm{AlCl}_{3}$ relative to some other catalysts in the same application had been reported by Corma (1997) to obeys the order $\mathrm{SiO}_{2}<\mathrm{Al}_{2} \mathrm{O}_{3}<\mathrm{SiO} . \mathrm{Al}_{2} \mathrm{O}_{3}<$ Zeolites $<\mathrm{AlCl}_{3}$. These catalysts are however abandoned due to environmental considerations. i.e causing disposal problems (Iglesia et al., 1993) and the necessary need for stronger and more stable solid acids catalysts that are economically cheaper.

B: ZIRCONIA CATALYSTS: Zirconium oxide (popularly known as zirconia, $\mathrm{ZrO}_{2}$ ), its sulphated and metal supported sulphated forms and its mixture with other oxides such as tungsten oxide were extensively studied to be useful in industrial alkanes isomerisation. In the early 2000's, Ono (2003) reported that $\mathrm{ZrO}_{2}$ was strongly acidic and active for the isomerisation of n-butane even at room temperature, especially when the catalysts is treated with $\mathrm{H}_{2} \mathrm{SO}_{4}$ and calcined at 850-920K-reference temperature (Ono, 2003). The relatively easy preparation nature of sulphated zirconia in addition to its low temperature high selectivity were found to play a significant role in the isomerisation of n-butane and n-pentane at temperatures lower than the room (Matsuhashi et al., 1999). The reaction progress involved initial mononuclear mechanism on the Lewis acids sites, $n$-butane was initially converted into a secondary butyl cation on the superacidic Lewis acid sites, followed by bimolecular formation of surface iso-butene on Bronsted acid sites and final hydrogenation to isobutane. This is generally illustrated in Fig 1.

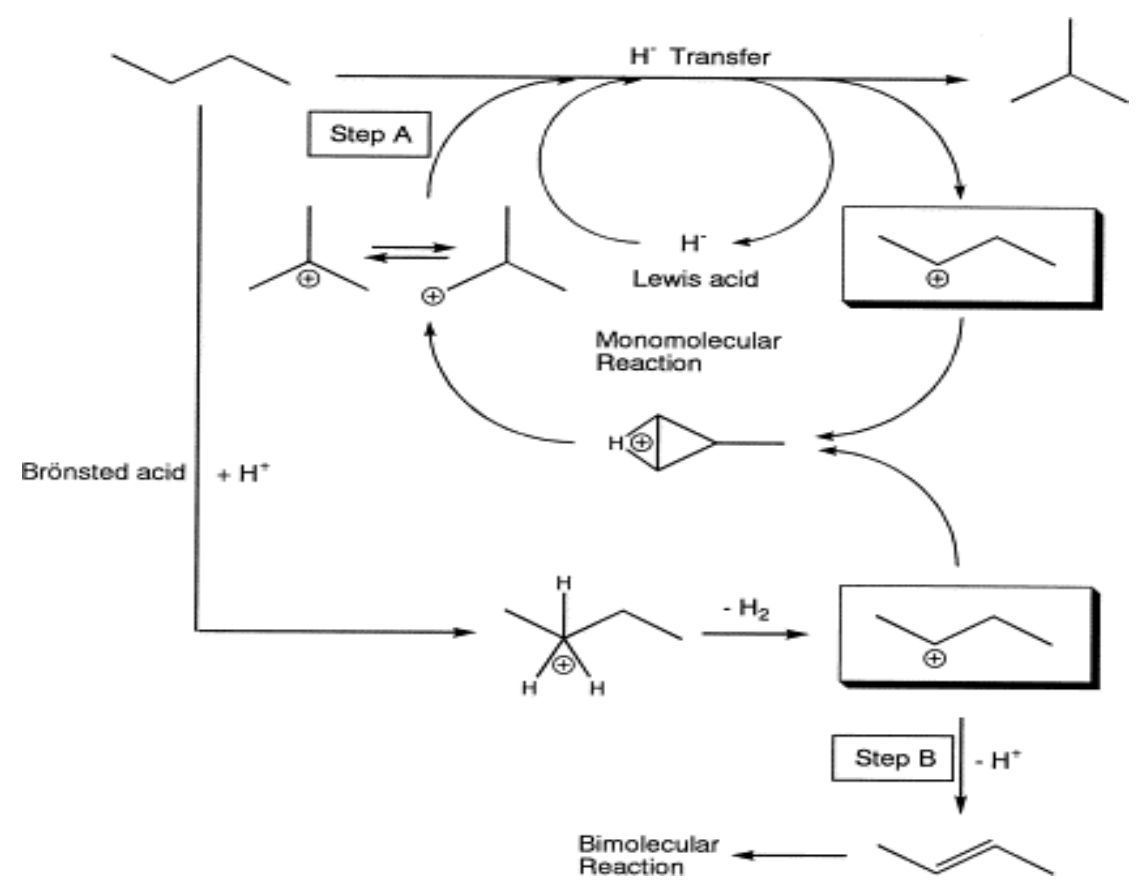

FIG. 1. DIAGRAMMATIC REPRESENTATION OF THE MECHANISM OF N-BUTANE ISOMERISATION OVER SULPHATED ZIRCONIA 
Studies by Vaudagna et al., (19997) indicated that loading of Pt on $\mathrm{WO}_{3} / \mathrm{ZrO}_{2}$ have positive effect on the rate and selectivity of alkanes isomerisation in the presence of hydrogen. The Pt metal was impregnated into the $\mathrm{WO}_{3} / \mathrm{ZrO}_{2}$, so that the catalysts contain $0.4 \%$ of $\mathrm{Pt}$ and the $\mathrm{Pt} / \mathrm{WO}_{3} / \mathrm{ZrO}_{2}$ calcined to a temperature of $830{ }^{\circ} \mathrm{C}$ (at $\left.2^{0} \mathrm{Cmin}^{-1}\right)$ for 3 hours. The specific surface area was found to increased to $>350 \mathrm{~m}^{2} / \mathrm{g}$ previously reported by Arata \& Hino (1988). A prominent shift to high pores diameter with maximum value around $5-8 \mathrm{~nm}$ was also achieved. The spectral data indicates the presence of amorphous species containing a double bond between tungsten and oxygen atom and the $\mathrm{H}_{2}$ chemisorption $\left(0.06 \mathrm{~cm}^{3} \mathrm{~g}^{-1}\right)$, leading to $24 \%$ Pt dispersion. High activity, stability and selectivity were generally found with the Pt loaded catalyst at shorter reaction time, particularly at the high calcination temperature.

In a trend similar to the one shown above, Inavov et al., (2002) reported the addition of Pt with further oxidation and mild reduction to promote the catalytic activity in $n$-hexane isomerization 10 times compared with a metal-free system $\left(\mathrm{WO}_{3}-\mathrm{SO}_{4} / \mathrm{ZrO}_{2}\right)$. The performance of the catalysts was tested after $0.5 \mathrm{~h}$ time-on-stream at noted temperatures for each experiment. Comparably, the $\mathrm{WO}_{3}-$ $\mathrm{SO}_{4} / \mathrm{ZrO}_{2}$ containing $15 \mathrm{wt} \%$ of $\mathrm{WO}_{4}{ }^{2-}$ calcined at $800^{\circ} \mathrm{C}$ shows no activity in the isomerisation of $n$-hexane and produced only $6.1 \%$ isohexane yield and $50.8 \%$ selectivity at $300^{\circ} \mathrm{C}$. However, incorporation of Pt metal produces $78.9 \%$ yield and selectivity of about $98.6 \%$ at $260{ }^{\circ} \mathrm{C}$ for both isohexane and isopentane.

In fact Ono (2003) shows that introduction of Pt metal can increase iso-alkane yield and selectivity from $6.1 \%$ and $50.8 \%$ to $78.9 \%$ and $98.6 \%$ respectively. It is therefore clear that the most important role of the Pt metal component is stabilizing the catalytic activity and to ensure higher selectivity for hydroisomerization. However, some general literature findings showed that the isomerisation activity of Zirconia catalysts declines rapidly at lower temperatures (Ahmad et al., 2003). This was reported to be attributed to formation of hydrocarbon surface deposits (coke), reduction of $\mathrm{Zr}^{4+}$ to $\mathrm{Zr}^{3+}$ by reacting hydrocarbon, $\mathrm{H}_{2} \mathrm{~S}$ formation reduction of surface sulphate groups, and surface poisoning by water (Comelli et al., 1995; Li \& Gonzalez, 1998; Vera et al., 1999). Similarly the acidity-activity relationship has not yet been fully evaluated (Ono, 2003).

C: HETEROPOLY ACIDS (HPAs): HPAs are considered as complex proton acids consisting of polyoxometalate anions (heteropolyanions) in which metal-oxygen octahedral form the basic structural units. Solid HPAs are known to form ionic crystals comprising of heteropolyanions, concentrations of $\mathrm{(H}^{+}, \mathrm{H}_{3} \mathrm{O}^{+}$, $\mathrm{H}_{5} \mathrm{O}_{2}{ }^{+}$, etc.) and hydration water. In line with their strong Brönsted acididity, HPAs possess three types of outer oxygen atoms serving as potential protonation units (Kozhevnikov,1998). Reactions involving solid HPAs are usually carried out with good care because they show properties close to those of solutions. For example Misono (1987) argued that due to the fact that these solids have discrete and mobile ionic structures they absorb a large amount of polar molecules, such as alcohols, ethers, amines, e.t.c., in the catalyst bulk, yielding HPA solvates.

Commercially available heteropoly acids such as $\mathrm{H}_{3} \mathrm{PW}_{12} \mathrm{O}_{40}$, $\mathrm{H}_{4} \mathrm{SiW}_{12} \mathrm{O}_{40}, \mathrm{H}_{3} \mathrm{PMO}_{12} \mathrm{O}_{40}$ and $\mathrm{H}_{4} \mathrm{SiM0}_{12} \mathrm{O}_{40}$, and their metal (s) promoted species are another category of solid acids catalysts with good potentials in siomerisation and other industrial processes. Kozhevnikov (1998) reported these compounds to have purely
Bronsted acidity and with stronger activity than some studied solid acid catalysts like $\mathrm{SiO}_{2}-\mathrm{Al}_{2} \mathrm{O}_{3}$, zeolites $\mathrm{HX}$ and $\mathrm{HY}$ and $\mathrm{H}_{3} \mathrm{PO}_{4} /$ $\mathrm{SiO}_{2}$. However, their fairly thermal stability causes lost of acidity especially at temperatures ranging from 350 to $465^{\circ} \mathrm{C}$ and also lead to difficulty of catalysts regeneration.

Travers et al., (2001) performed the isomerisation of n-hexane using $\mathrm{Cs}_{x} \mathrm{H}_{3-\mathrm{x}} \mathrm{PW}_{12} \mathrm{O}_{40}$ catalysts with $\mathrm{Pt}$ metal as a promoter. In addition to selectivity for dibranched isomers, the overall catalytic performance was comparably very close to that of industrial zeolite catalysts under similar reaction conditions. The catalyst was prepared by mixing stochiometric ratios of $\mathrm{H}_{3} \mathrm{PW}_{12} \mathrm{O}_{40} \cdot n \mathrm{H}_{2} \mathrm{O}$ and $\mathrm{Cs}_{3} \mathrm{PW}_{12} \mathrm{O}_{40}$ followed by pre-treatment at different temperatures under various atmospheres of nitrogen, hydrogen and air. Pt metal was also introduced by similar means. $n$-Hexane isomerisation was then carried out in a fixed bed micro-reactor at a total pressure of 4 bar, temperature ranging from 180 to $220^{\circ} \mathrm{C}$, and molar hydrogen to $n$-hexane ratio of 10 (Travers et al., 2001). The reaction obeyed the bifunctionl mechanism discussed earlier. On the other hand the presence of the Cs salt leads to highest microporosity and a Brönsted/Lewis ratio close to 6 . The acidity was promoted by $\mathrm{H}_{2}$ pre-treatment both by the protons resulting from $\mathrm{W}^{6+}$ reduction and by the intermediate of water molecules generated through the reduction step.

In recent years, Kozhevnikov (2007) showed the modification of HPAs with platinum group metals (PGM) like Pt and Pd to have positive effect in enhancing catalysts thermal stability and HPAs regeneration, especially at metals loading of $0.3 \%$. In a related development the addition of $\mathrm{Pd}$ appeared to enhance coke combustion. It was observed that as the temperature decreases, the higher the $\mathrm{Pd}$ loading the lower the temperature of coke combustion. For example at $2 \% \mathrm{Pd}$ loading, coke burns at $350^{\circ} \mathrm{C}$, which is well below the temperature of $\mathrm{H}_{3} \mathrm{PW}_{12} \mathrm{O}_{40}$ decomposition. HPAs catalysts have many important characteristics that account for their economic and environmental attraction. Contrary to the network structures of zeolites or metal oxides, HPAs have discrete ionic structures, comprising fairly basic mobile structural units (Heteropoly anions and concentration; $\mathrm{H}^{+}, \mathrm{H}_{3} \mathrm{O}^{+}, \mathrm{H}_{5} \mathrm{O}_{2}+$ etc). This structure allows high proton mobility and the corresponding heteropoly anions can stabilise cationic paraffin intermediates (Kozhevnikov, 1998). Similarly, changing chemical composition can easily vary their acid-base and redox characteristics. However, Essayem et al., (2003) argued that a simultaneous presence of platinum and hydrogen inhibits and suppresses the isomerisation of n-pentane at 423K over HPA-based catalysts.

D: MOLYBDENUM OXIDE BASED CATALYSTS: Molybdenum oxide based catalysts such as partially reduced $\mathrm{MoO}_{3}$ and Molybdenum oxycarbides were also reported to play a considerable role in n-alkanes isomerisation. Matsuda et al., (1997a) carried out a study on the isomerisation of n-pentane on molybdenum oxide treated with hydrogen as a reducing agent. Unreduced $\mathrm{MoO}_{3}$ was found to be inactive at the employed reaction conditions (573K and atmospheric pressure). However, $\mathrm{H}_{2}$ reduction of $\mathrm{MoO}_{3}$ at higher temperature $(623 \mathrm{~K})$ promoted both the isomerisation activity and selectivity. In comparative term, the reduced catalyst shows appreciable activity higher than a tested bifunctional zeolite $(0.5 \mathrm{wt} \% / \mathrm{Pt} / \mathrm{USY}$ Zeolite). The outcome of the study implies that the reduced $\mathrm{MoO}_{3}$ catalyst successfully isomerises the n-pentane by conventional bifunctional mechanism 
and that the catalyst maybe employed as a substitute to the bifunctionl zeolite. Shortly after that report, Matsuda et al., (1997b) reported unreduced $\mathrm{MoO}_{3}$ to be significantly active and selective for the same reaction at $623 \mathrm{~K}$ and $1 \mathrm{~atm}$ pressure after long induction period of about 5-10 hours. They also found Ni (10wt\%) to be effective in stabilising the isomerisation activity without a change in selectivity under the same reaction conditions.

Isomerisation of higher alkane (n-octane) over molybdenum oxycarbide catalyst produced insitu from $\mathrm{MoO}_{3}$ was also reported (York et a l., 1997) and the experimental results compared with that of Pt-supported bifunctional catalyst (Pt/ $\beta$-Zeolite). It was found that very high selectivity $(>90 \%)$ to the mono and di-methyl isomers produced can be achieved over the molybdenum-based catalysts. The catalyst also shows high resistance to sulphur and nitrogen poisons present in the feedstock used.

The application of high specific surface area $\mathrm{MoO}_{3}$-CarbonModified catalyst for the selective isomerisation of n-butane was similarly conducted by De gallo et al., (1997). Considering the induction period, the upper $\mathrm{MoO}_{3}$ layers show inactivity for the isomerization reaction, and this agreed with previous studies for isomerization reactions carried out with heavier hydrocarbons ( $n$ hexane to n-octane) using similar catalyst (Leudox et al., 1996). The modification accounts for the improved surface area to $100 \mathrm{~m}^{2}$ $\mathrm{g}^{-1} \mathrm{MoO}_{3}$-carbon-modified catalyst, which was active and very selective for $n$-butane isomerization, leading to about $95 \%$ conversion. Only slight deactivation was encountered after $48 \mathrm{hr}$ of reaction at $350{ }^{\circ} \mathrm{C}$ and also a low decrease in the n-butane selectivity due to formation of small carbide phase.

In recent years, Bouchy et al., (2000), after slightly modified the above procedure by De gallo et al., (1997) synthesized molybdenum oxycarbohydride catalyst by reacting unsupported $\mathrm{MoO}_{3}$ with a $\mathrm{H}_{2} / n$-butane flow of $55 \mathrm{ml} / \mathrm{min}, \mathrm{H}_{2} / n$-butane=10 at the same temperature. The $n$-butane conversion and isomerisation selectivity obtained over unsupported $\mathrm{MoO}_{3}$ were similarly negligible for long induction period before the conversion slowly increased with time on stream to reach a steady-state after about $24 \mathrm{hr}$. Such a period is the time required to convert the unsupported $\mathrm{MoO}_{3}$ to the oxycarbohydride. The selectivity was generally high (>90\%) after the $24 \mathrm{hr}$ period.

In view of these, it is clear that, molybdenum oxide-based catalysts have good selectivity and activity for n-butane, n-pentane and noctane isomerisation. Similarly, they posed little recycle and disposal problems compared to Friedel crafts catalysts. Thus, they have future potentials for environmental management. However, the isomerisation mechanism over these catalysts received only little attention and therefore requires further investigations, as reliable details are not yet resolved.

E: ZEOLITE BASED BIFUNCTIONAL CATALYSTS: The exploitation of zeolites as special microporous solids for catalysing refining processes has been an industrial issue since the synthesis of A zeolite in 1949 (Macilli, 2004). From about 1970 to 1980 these compounds have gradually found applications in areas of fine chemicals and petrochemical industry. Most recent development in catalysis however shows that zeolite materials loaded with Pt or Pd metal could be employed industrially for an efficient method of isomerising n-alkanes (mostly n-pentane to n-heptane) to corresponding iso-alkanes for producing high-octane gasoline. The reaction is carried out at high hydrogen pressure $\left(20-70 \mathrm{Kgcm}^{-2}\right)$, which is too much to be consumed in the process. Thus, the reaction is called "hydroisomerisation" due to the presence of hydrogen. These catalysts are called bifunctional because they both act as acid catalysts and also hydrogenationdehdydrogenation catalysts. They show prominently high activity and adequate stability as well.

The mechanism of the process consists of the following three elementary steps.

Initially, the n-alkane is dehydrogenated on the metal surface to a corresponding iso-alkane (equation 1).

e. g. $\mathrm{n}-\mathrm{C}_{6} \mathrm{H}_{14} \longleftrightarrow \mathrm{n}-\mathrm{C}_{6} \mathrm{H}_{12}+\mathrm{H}_{2}$ (on metal)

The alkene produced is then adsorbed on the Bronsted acid sites, yielding carbenium ion in the transition state, which isomerises and consequently desorbs (equation 2 to 4 ).

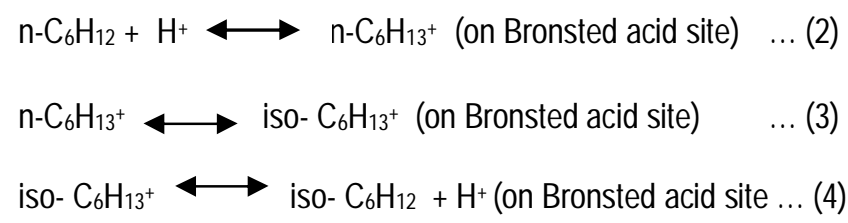

Finally, the iso-alkene produced is hydrogenated on the metal surface to an iso-alkane (equation 5).

iso- $\mathrm{C}_{6} \mathrm{H}_{12}+\mathrm{H}_{2} \longleftrightarrow$ iso- $\mathrm{C}_{6} \mathrm{H}_{14}$ (on metal)

This clearly implies that, the metal catalyses the hydrogenationdehydrogenation steps while the zeolite catalyses the isomerisation step. Similarly from equations 1 to 5 , the presence of metal loading equilibrates the hydrogenation/dehydrogenation steps and that the pore sizes of the zeolite affect the isomerisation step.

Chao et al., (1996) carried out an isomerisation of n-pentane, nhexane and $n$-heptane on platinum-hydrogen beta catalysts (Pt/HBEA) and on platinum-hydrogen mordenite catalysts (Pt/HMOR) of various silica-aluminum ratios at temperatures ranging from 190 to $310^{\circ} \mathrm{C}$. Good dispersion of Pt on the zeolites with particle sizes of 1.3-2.6nm was observed. Larger crystallites with $5 \mathrm{~nm}$ sizes were also encountered with the $0.5 \% \mathrm{Pt} / \mathrm{HMOR}(18)$ and $0.5 \% \mathrm{Pt} / \mathrm{HBEA}(11)$. Pt/HBEA catalyst show higher activity and selectivity for all the paraffins, consequent from its large pore sizes. However, magnesium exchange or de-alumination can improve the activity and selectivity of the Pt/HMOR in n-pentane isomerisation.

A related development to this was the isomerisation of $n$-hexane only in the same year over the same wt\% of Pt loaded to Hß, ZSM5 and $\mathrm{H}$-dealuminated mordenite catalysts with respective Si/Al ratio of 23, 30 and 11 by Yashima et al., (1996). Although other isomers were detected, the major product was 2,2-dimethyl butane with selectivity of formation obeying the order $\mathrm{Pt} / \mathrm{H}-\mathrm{ZSM}-5<\mathrm{Pt} / \mathrm{HM}$ $<\mathrm{Pt} / \mathrm{H} ß$ because ZSM-5 pore size is lower than the molecular size of 2,2-dimethyl butane. It was generally observed that high activity and selectivity can be obtained with $\mathrm{Pt} / \mathrm{H} ß$ when an appropriate balance between Pt loading and $\mathrm{H} ß$ acidity is maintained.

In another study relevant to this, Soualah et al., (2008) hydroisomerised higher alkanes (n-decane, $n$-tetradecane and $n$ hexadecane) at $220^{\circ} \mathrm{C}$ using Pt loaded HBEA, HMCM-22 and 
HZSM-5 zeolites. Platinum metal dispersion over the catalysts was found to be $80 \%$ on HBEA, $65 \%$ on MCM- 22 and $70 \%$ on ZSM-5. Although there was formation of multibranched and cracked products and a decreased in activity with $n$-alkane chain length, all the catalysts showed high activity with PtHBEA being the most active in all the cases. These outcome correlates with result of studies by Claude \& Martens (2000) for small pores zeolite-based catalysts.

About 10 years after the previous studies of Chao and co-workers conducted in 1996, Li et al., (2006) incorporated Pd metal instead of previously used $\mathrm{Pt}$ metal to hydroisomerise n-pentane over $\mathrm{Pd} / \mathrm{ZSM}-5, \mathrm{Pd} / \mathrm{\beta}, \mathrm{Pd} / \mathrm{USY}$ and a hybrid of $\mathrm{Pd} / \mathrm{SiO}_{2}$ and USY catalysts with fixed $\mathrm{Pd}$ loading of $0.5 \mathrm{wt} \%$. After successful synthesis of the catalysts from their commercially un-supported forms by ion exchange with aqueous $\left[\mathrm{Pd}\left(\mathrm{NH}_{3}\right)_{4}\right] \mathrm{Cl}_{2}$, n-pentane isomerisation was performed at $523 \mathrm{~K}, 0.5 \mathrm{MPa}$ pressure and $\mathrm{H}_{2} / \mathrm{n}$ pentane ratio of 12 in a continuous flow fixed bed reactor. Similar result to the cases of $\mathrm{Pt}$ was found. $\mathrm{Pd} / \beta$ showed the highest activity while $\mathrm{Pd} / \mathrm{ZSM}-5$ shows the lowest activity. It was also evident that both $P d / \beta$ and $P d / U S Y$ showed very significant selectivities (>90\%) but the $\mathrm{Pd} / \mathrm{ZSM}-5$ selectivity was very low, yielding cracked hydrocarbon products. Separate forms of $\mathrm{Pd} / \mathrm{SiO}_{2}$ and USY does not show any reliable activity even at variable temperatures but the hybrid catalyst $\left(0.5 \mathrm{wt} \% \mathrm{Pd} / \mathrm{SiO}_{2}\right.$ and USY) recorded much higher activity at various temperatures. It could therefore be interpreted that $\mathrm{Pd}$ and acid balance is necessary for n-hepatane hydroisomerisation. Comparably the $\mathrm{Pd}$ influence in the reaction is similar to that reported for Pt (Chao et al., 1996; Yashima et al., 1996; Soualah et al., 2008).

As the hydroisomerisation of $n$-alkanes in gasoline with metalloaded zeolites for upgrading its octane number consistently attracts scholarly attention, especially considering the relevance to environmental management and meeting the fuel requirement of modern high performance gasoline engines, further investigations were carried out to evaluate the influence of some important parameters on the various aspect of the process. Wang et al., (1997) tested the effect of parameters like reaction temperature, acid sites (Si/Al ratio), and contact time (W/F) on the catalytic activity of Pt-loaded $\mathrm{H} \beta$ catalysts during the isomerisation of $n$ heptane. The Pt-loaded $\mathrm{H} \beta$ zeolites with Si/Al ratios of 18, 21, 23 and 30 were prepared by stepwise ion exchanged of hydrothermally synthesised zeolites with ammonium nitrate solution and $\mathrm{Pt}\left(\mathrm{NH}_{3}\right)_{4} \mathrm{Cl}_{2}$ solution at $98^{\circ} \mathrm{C}$ under stirring. The reaction was monitored in a continuous flow fixed bed reactor at $1 \mathrm{~atm}$ and $\mathrm{H}_{2} / \mathrm{n}$ heptane ratio of 7.5 . The experimental results indicated that highest yield of isomerised products was obtained at $210^{\circ} \mathrm{C}$ and the conversion of $n$-heptane increased with contact time (W/F) especially at values lower than $1.5 \mathrm{ghmol}^{-1}$, while the selectivity to isomers decreased. An interesting finding is that $\mathrm{Pt} / \mathrm{H} \beta$ catalyst maintained a promising stability for $78 \mathrm{hr}$ at a temperature of $220^{\circ} \mathrm{C}$. For the Pt loadings of 0.1 to $3 w t \%$, an increase in metal doping caused increased in isomers selectivity at $230^{\circ} \mathrm{C}$ while the conversion of $n$-heptane and fraction of multiple isomers does not depend on metal loadings. Under constant reaction conditions the conversion decreased with increase in Si/Al ratio while the selectivity to isomers at the same conversion follows the order $\mathrm{Pt} / \mathrm{H} \beta 18<\mathrm{Pt} / \mathrm{H} \beta 21<\mathrm{Pt} / \mathrm{H} \beta 30$. The later was attributed to the fact that high Si/Al ratios relate to lower acid density, and that a generated intermediate alkene on Pt site contact only few acid sites between any two Pt sites leading to a favourable shift in the formation of isomerised alkanes.

Now it is clear that good isomerisation activity is obtained when the hydrogenation activity of the metal $(\mathrm{Pt} / \mathrm{Pd})$ and the Bronsted acid activity of the zeolite are in balance. In essence, the concentration of the metal and strength of Bronsted acid sites determines the activity of the catalysts by controlling the concentration and lifetime of the carbenium ions and the relative ratio of $\mathrm{C}-\mathrm{C}$ bond cleavage versus isomerisation (Fernandes et al., 1998; Martens et al., 2001; Ono, 2003; Caeiro et al., 2006). Therefore, coupling the various Literature findings with the chemistry of the hydroisomerisation mechanism (equations 1 to 5), it can be inferred that modification of the acid and textural properties of the zeolite catalysts will have positive effect on the reaction rate, isomerisation yield, isomers selectivity, and over coming side reactions like cracking and aromatisation.

For example, Mao \& Saberi (2000) found that $\mathrm{Al}^{3+}$ species when incorporated by impregnation into $\mathrm{Pt} / \mathrm{H}-\mathrm{Y}$-Zeolite significantly increases the yield of branched paraffins and also decreased the formation of cracked hydrocarbons. The content of $\mathrm{Al}$ and Pt of all the final catalysts from ASS, TPD and X-ray diffraction studies were found to be $1-7 w t \%$ and $1 \mathrm{wt} \%$ respectively. Experimental data clearly indicates that, aluminum species when incorporated in quite small amounts $(<2 w t \%)$ has a positive effect on the production of $\left(\mathrm{C}_{5}-\mathrm{C}_{7}\right)$ branched paraffins. A quite similarly result was obtained when $\mathrm{Al}$ metal was substituted with equimolar concentrations of $\mathrm{Zn}$ and $\mathrm{Cd}$. The chemical interpretation to this is that that the metal species ( $\mathrm{Al}, \mathrm{Zn}$ or $\mathrm{Cd}$ ) when incorporated simultaneously with the $\mathrm{Pt}$ species, are merely deposited (chemisorbed) onto the zeolite (oxidic) surface next to the Pt sites but not that Pt and Al species can undergo competitive or selective adsorption on the zeolite surface reported in some literatures (Weitkamp et al., 1983; Taylor \& Petty, 1994; Parlitz et al., 1995; Lugstein et al., 1999). However, the incorporation does not contribute to the variation of the density of the surface acid sites.

From another angle, U.S. researchers Apelian \& Kennedy (1991) showed the addition of nitrogen compounds to have positive effect on the equilibriation of zeolite hydrocracking catalysts such as Beta, X, USY, ZSM-4 and ZSM-20 zeolites loaded with $0.5 \mathrm{wt} \%$ of Pt or Pd metal. According to them, 1wt\% each of ammonia, alkylamines and alkanalomines like ethanolamines have found special consideration in this case. The metal could be introduced by the usual ion exchange or impregnation method while the reaction in a fixed bed continuous flow reactor at 260-455 ${ }^{\circ} \mathrm{C}$ and up to $17340 \mathrm{kPa}$. The modification property of the direct nitrogen compound addition was indicative by the decreased in hydrogenation activity upon their introduction.

Ramos et al., (2005) tested the effect of Bentonite agglomeration over Pd-ZSM-5 (PdZSM-5), Pd-mordenite (PdMOR), and Pd-beta (PdBETA) zeolites with respective Si/Al ratios of 15.60, 10.40 and 13.0 during the hydroisomerisation of $a C_{7}$ to $C_{8}$ alkanes. The results indicated no blocking of the zeolite channels by the metal or by the bentonite and the experimental values of the surface area were in good agreement with the theoretical ones. However, a decreased in the number of strong acid sites observed with the mordenite catalyst could be due to solid-state ion exchange between the zeolite protons and the bentonite sodium cations. 
Although the same products were obtained, the overall n-heptane and n-octane conversion increased in the order PdZSM-5Bent < PdMORBent $<$ PdBETABent. The effect of bentonite agglomeration can therefore be attributed to extra frame work aluminium species generated, responsible for the optimal conversion and the consequent high octane number especially with agglomerated beta catalyst (De Lucas et al., 2004). The extra framework aluminium species could interact with the structural Brönsted acid sites, enhancing their acid strength through a synergetic effect and, consequently, making them much more active for the hydroisomerisation (De Lucas et al., 2004; De Lucas et al., 2005; Ramos et al., 2005). The absence of methane and ethane in the product indicates that the modification does not contribute to cracking. Similarly, the research octane number of the product was found to be significantly higher with the agglomerated catalysts.

Addition of $\left(\mathrm{NH}_{4}\right)_{2} \mathrm{SO}_{4}$ was also found to enhanced the acidity and activity of zeolites due to the formation of aluminium sulphate species. This was supported by the work of Lei et al., (1999) conducted eight years after the $\mathrm{N}$-compouds studies by Apelian \& Kennedy (1991). Lei and his co-workers successfully sulfated $\mathrm{H}$ mordenite zeolite by immersing the zeolite in $0.5 \mathrm{~mol} / /\left(\mathrm{NH}_{4}\right)_{2} \mathrm{SO}_{4}$ solution for $30 \mathrm{~min}$, followed by filtration, drying at $110^{\circ} \mathrm{C}$ and calcination at $650^{\circ} \mathrm{C}$ for $4 \mathrm{hr}$ and tested its activity relative to that of unsulfated $\mathrm{H}$-mordenite for pentane hydroisomerization at $75^{\circ} \mathrm{C}$ in continuous flow fixed bed reactor. They concluded that the acidity of synthetic mordenites can be enhanced by sulfation and that extra-framework aluminium species generated in synthesis or added post synthesis may combine with $\mathrm{SO}^{2-}{ }_{4}$ forming superacidic surface sulfate complex on the zeolites, the acidity of which depends on the nature of the extra-framework aluminium species and they are very active for $n$-pentane isomerization at $75^{\circ} \mathrm{C}$. In a similar trend, activities of sulfated mordenite catalysts for toluene disproportionation and 0 -xylene isomerization are higher than those of the original H-mordenites (Lei et al., 1999).

The influence of $\mathrm{H}_{2} \mathrm{~S}$ as a gaseous modifier on the activity of $\mathrm{Pt}$ (1wt\%)/HBEA zeolites with respective Si/Al ratios of 12.5 and 9.5 (obtained by the normal ion exchange method) in the hydroisomerisation of $n$-pentane was also recently reported by Wolt et al., (2006). The catalysts were characterised by both spectroscopic and chromatographic methods. No variation in the zeolites crystallinity was observed after the sulfation and that the sulphate species promoted the concentration of acid sites in all zeolites by converting $(\mathrm{AlO})_{3} \mathrm{~S}=\mathrm{O}$ species to Brønsted acidic (AlO) ${ }_{2} \mathrm{SOO}-\mathrm{H}+$ groups and the creation of new $\mathrm{OH}$ groups affiliated with sulfate that are not readily detected because of hydrogen bonding (Saur et al., 1986; Li et al., 2004). The sulfation effect could simply be described as it generates sulfate groups and Brønsted acidic sites, modifies the supported metal particles, and leads to higher activity and selectivity for pentane hydroisomerization at all the temperatures studied.

\section{CONCLUSION}

From this survey, the following conclusions could be drawn. Catalysts such as Freidel crafts, Zirconias, Heteropoly acids, Molybdenum oxide-based, chlorinated aluminium oxide and bifunctional zeolites are employed for industrial alkanes isomerisation. The Freidel craft catalysts have reasonable activity but are currently abandoned due to corrosion and disposal problems as well as economic limitations. $\mathrm{MoO}_{3}$-based catalysts show reasonable activity only after certain induction period but could show good resistance to sulphur and nitrogen present in a reaction stream. However, although active and selective their mechanism of application and acidity-activity relationship is not fully evaluated and cracking and aromatisation may occur as side reactions during hydroisomerisation.

Zeolite-based bifunctional catalysts are currently gaining industrial attention, especially in hydroisomerisation for improving octane number of gasoline. Although the catalysts are of high acidity and activity, their textural properties as well as the acidity and isomerisation rate could be improved by the introduction of important modifiers to get optimal performance. Studies carried out concentrated mostly on the used of solid modifiers like aluminium sulphate, ammonium sulphate, Bentonite etc. Both Pt and Pd metals have comparably the same effect in bifunctional hydroisomerisation at all temperatures and that $\mathrm{Pt}$ or $\mathrm{Pd}$ beta zeolites showed the highest activity and selectivity among other studied zeolites due to their large pore sizes. Thus, the pore size of a zeolite has significant effect on the hydroisomerisation process.

\section{ACKNOWLEDGEMENT}

Full funding of Galadima's PhD studentship at Aberdeen University by Petroleum Technology Development Fund (PTDF) Nigeria is warmly acknowledged.

\section{REFERENCES}

Ahmad, R., Melsheimer, J., Jontoff, F. C., \& Schlogl, R. (2003). Isomerisation of $n$-butane and $n$-penatane in the presence of sulphated zirconia: Formation of surface deposits investigated by insitu UV-vis diffuses reflectance spectroscopy. Journal of Catalysis, 218(2): 365-374.

Apelian, M. R., Kennedy, C. R. (1991). Modification of bifunctional catalysts activity in hydroprocessing. US Patent 5,062,943.

Arata, K. and M. Hino In: M.J. Phillips \& M. Ternan (editors), (1988). Oxide Catalysts and Catalyst Development, Proceedings of the 9th International Congress on Catalysis, The Chemical Institute of Canada, Ontario, p. 1727.

Bouchy, C., Pham-Huu, C., Heinrich B., Derouane, E. G., Hamid, S. B. D \& Ledoux, M. J. (2000). Insitu TPO,TPD and XRD chracterisation of amolybdenum oxycarbohydride catalyst for nbutane isomerisation. Applied Catalysis A: General, 215(1-2):175184.

Caeiro, G., Carvalho, R. H., Wang, X., Lemos, M.A.N.D.A., Lemos, F., Gusinet, M., \& Ribeiro, F.R. (2006). Activation of $\mathrm{C}_{2}-\mathrm{C}_{4}$ alaknes over acid and bifunctional zeolite catalysts. Journal of Molecular catalysis A: Chemical, 255(1-2) 131-158.

Chao, K., Wu, H., Leu., L. (1996). Hydroisomerisation of light normal paraffins over series of Platinum-loaded mordenite and beta catalysts. Applied Catalysis A: General, 143, 223-243.

Chica, A., \& Corma, A. (1999). Hydroisomerisation of pentane, hexane and heptanes for improving octane number of gasoline. Journal of Catalysis, 187:167-176. 
Claude, M. C. \& Martens, J. A. (2000). Monomethyl branching of long n-alkanes in the range from decane to tetracosane on $\mathrm{Pt} / \mathrm{H}$ ZSM-22 bifunctional catalyst. Journal of Catalysis, 190 (1): 39-48.

Corma, A. (1997). Solid Acid Catalysts. Current Opinion in Solid State and Materials Science, 2(1):63-75.

Comelli, R. A., Vera, C. R., \& Parera, J. M. (1995). Influence of $\mathrm{ZrO}_{2}$ crystalline structure and sulphate ion on the catalytic activity of $\mathrm{SO}_{4}{ }^{2-} \mathrm{ZrO}_{2}$. Journal of Catalysis, 151: 96-101.

Del Gallo, P, Meunier, F.. Pham-Huu, C., Crouzet, C. \& Ledoux. M. J. (1997). Selective $n$-Butane Isomerization over High Specific Surface Area $\mathrm{MoO}_{3}$-Carbon-Modified Catalyst. Industrial and Engineering Chemistry Research, 36 (10): 4166-4175.

De Lucas, A.; Valverde, J. L.; Sánchez, P.; Dorado, F.; Ramos, M. J. (2004). Influence of the binder on the n-octane hydroisomerization over palladium-containing zeolite catalysts. Industrial and Engineering Chemistry Research, 43, 8217.

De Lucas, A.; Valverde, J. L.; Sánchez, P.; Dorado, F.; Ramos, M. J. (2005). Hydroisomerization of $n$-octane over platinum catalysts with or without binder. Applied Catalysis, 282, 15.

Essayem, N., Taarit, Y. B., Feche, C., Gayraud, P.Y., Sapaly, G \& Naccache, C. (2003). Comparative study of n-pentane isomeristion over solid acid catalysts, heteropoly acids, sulphated zirconia, and Mordenite.: Dependence on Pt and Hydrogen addition. Journal of Catalysis, 219(1):97-106.

Eswaramoorthi, I., Sundaramurthy, V., Lingappan, N. (2004). Hydroisomerisation of C6 to C7 n-alkanes over Pt loaded zirconium containing Al-MCM-41 molecular sieves. Microporous and Mesoporous Materials, 71: 109-115.

Fernandes, L. D., Monteiro, J. L. F., Sousa-Aguair, E. F., Martinez, A. \& Corma, A. (1998). Ethylbenzene hydroisomerisation over bifunctional zeolite based catalysts: The influence of framework and extra frame work composition and zeolite structure. Journal of Catalysis, 177(2): 363-377.

Iglesia, E., Soled, S. L. Kramer, G. M. (1993). Isomerisation of alkanes on sulphated zirconia. Promotion by Pt and by Adamantyl hydride Transfer species. Journal of Catalysis. 144:238-253.

Inavov, A. V., Vasina, T. V., Masloboishchikova, O. V. (2002). Isomerisation of $n$-alkanes on $\mathrm{Pt} / \mathrm{WO}_{3}-\mathrm{SO}_{4} / \mathrm{ZrO}_{2}$ systems. Catalysis Today, 73: 95-103.

Karthikeyan, D., Lingappan, N., Siv asankar, B., Jabarathinam, N. J. (2008). Activity and selectivity for hydroisomerisation of ndecane over Ni-impregnated $\mathrm{Pt} / \mathrm{H}$-mordenite catalysts. Applied Catalysis A: General, 345(1):18-27.

Lugstein, A.,. Jentys, A. \& Vinek, H. (1999). Hydroisomerization and cracking of $n$-octane and $\mathrm{C}_{8}$ isomers on Ni-containing zeolites. Applied Catalysis A: General, 176(1) 119-128.
Kozhevnikov, I. V. (1998). Catalysis by heteropoly acids and multicomponent poly oxy metalates in Liquid-phase reactions. Chemical Reviews, 98:171-198.

Kozhevnikov, I. V. (2007). Sustainable heterogeneous acid catalysis by heteropoly acids. Journal of Molecular Catalysis A: Chemical, 262 (1-2):86-92.

Li, B., \& Gonzalez, R. D. (1998). The effect of coke deposition on the deactivation of sulphated zirconia catalysts. Applied Catalysts A: General, 174:109-119.

Li, X., Husain, Y.C. R., \& Watson, J. T. (2004) Integration of hydrogen/deuterium exchange and cyanylation-based methodology for conformational studies of cystinyl proteins. Analytical Biochemistry 331, 130-137.

Li, X., Yang, J. Liu, Z. Asami, K. \& Fujimoto, K. (2006). Selective Hydroconversion of $n$-Heptane over Pd-supported Zeolites and Pd-containing Hybrid Catalyst. Journal of the Japan Petroleum Institute, 49(2) 86-90.

Ledoux, M. J.; Pham-Huu, C.; York, A. P. E.; Blekkan, E. A.; Delporte, P.; Del Gallo, P. (1996). Study of the Isomerization of $C_{6}$ and $\mathrm{C}_{6+}$ Alkanes over Molydenum Oxycarbide Catalysts. In The Chemistry of Transition Metal Carbides and Nitrides; Oyama, S. T., Ed.; Blackie: Glasgow, U.K.

Lei, T., J. S. Xu \& Gao, Z. (1999). Acidity enhancement of Hmordenite by sulfation. Materials Chemistry and Physics, 60(2) 177-181.

Macilli, C. R. (2004). Zeolites in the Petroleum Industry. Encyclopedia of Supramolecular Chemistry. DOI: 10.1081/EESMC-120012811.

Martins, A., Silva, J. M., Ribeiro, F. R., Guisnet, M., Ribeiro, M. F. (2008). n-Haxane hydroisomerisation overbifunctional Pt/MCM-22 catalysts. Influence of the mode of Pt introduction. Studies in Surface Science and Catalysis, 174(2):1135-1138.

Martens, J. A., Vanbutsele, G., Jabobs, P. A., Denayer, J., Ocakoglu, R., Baron, G., Arroyo, J. M. A., Thybaut, J., Marin, G. B. (2001). Evidences for pore mouth and key-lock catalysis in hydroisomerisation of long n-alkanes over 10-ring tubular pore bifunctional zeolites. Catalysis Today, 62(2-4):111-116.

Matsuda, T., Shiro, H., Sakagami, H., \& Takahashi, N. (1997a). Isomerisation of heptanes on molybdenum oxides treated with hydrogen. Catalysis Letters, 42(2):99-103.

Matsuda, T., Sakagami, H. \& Takashi, N. (1997b). Isomerisation of heptanes on Molybdenum oxide catalysts with a small amount of Nickel. Journal of Chemical Socierty, Faradays Transaction, 93(12):2225-2229.

Matsuhashi, H., Shibata, H., Nakamaru, H. \& Arata, K. (1999). Skeletal isomerisation mechanism of alkanes over solid super acids of sulphated zirconia. Applied catalysis A: General, 187(1):99-106. 
Mao, R. L. V. \& Saberi, M. A. (2000). Catalysts for hydroisomerisation of $n$-heptane, prepared according to the concept of triangular configuration (acid/metal/desorption transfer promoting sites). Applied Catalysis A: General, 199(1):99-107.

Misono, M. (1987). Heterogeneous Catalysis by Heteropoly Compounds of Molybdenum and Tungsten. Catalysis Reviews, 29(1-2):269-321.

Ono, Y. (2003). A survey of mechanism in catalytic isomerisation of alkanes. Catalysis Today, 81, 3-16., 44(24):9050-9058.

Parlitz, B., Schreier, E., Zubowa, H. L., Eckelt, R., Lieske, E., Lischke, G. \& Fricke, R. (1995). Isomerization of $n$-Heptane over $\mathrm{Pd}$-Loaded Silico-Alumino-Phosphate Molecular Sieves. Journal of Catalysis, 155(1):1-11.

Ramos, M. J., Gomez, J. P., Dorado, F., Sanchez, P., \& Valverde, J. L. (2005). Hydroisomerisation of a Refinery Naptha stream over Agglomerated Pd-Zeolites. Industrial and Engineering Chemistry Research, 44 (24):9050-9058.

Saur, O. M., Bensitel, A. ,Saad, B. M. Lavalley, J.C. Tripand, C. P., Morrowt, B. A. (1986). The Structure and Stability of Sulfated Alumina and Titania. Journal of Catalysis, 9:104-110.

Serra, J. M., Chica, A., Corma, A. (2003). Development of a low temperature light paraffin isomerisation catalysts with improved resistance to water and sulphur by combanitorial method. Applied Catalysis A: General, 239, 35-42.

Soualah, A. Lemberton, J. L. Pinard, Chater, L. Magnoux, L. P. \& Moljord, K. (2008). Hydroisomerisation of long chain n-alkanes on bifunctional Pt/Zeolite catalysts: Effect of zeolite structure on the product selectivity and on the reaction mechanism. Applied Catalysis A: General, 336(1-2):23-28.
Taylor, R.J. \& Petty, R. H. (1994). Selective hydroisomerization of long chain normal paraffins. Applied Catalyis A: General, 119(1) 121-138

Travers, C., Essayemb, N., Delaga, M. \& Quelen, S. (2001). Heteroploy anions based catalysts for paraffins isomerisation, Catalysis Today, 65(2-4):355-361.

Vandagna, S. R., Comelli, R. A., Figoli, N. S. (1997). Influence of the tungsten oxide precursor on $\mathrm{WOx}_{-} \mathrm{ZrO}_{2}$ and $\mathrm{Pt} / \mathrm{WOx}-\mathrm{ZrO}_{2}$ properties. Applied Catalysis A; General, 164:265-280.

Vera, C. R., Pieck, C. L., Shimizu, K., Querini, C. A., \& Parera, J. M. (1999). Coking of $\mathrm{SO}_{4}{ }^{2-}-\mathrm{ZrO}_{2}$ catalysts during isomerisation of n-butane and its relation to the reaction mechanism. Journal of Catalysis, 187(1):39-49.

Wang, Z. B., Kamo, A. Yoneda, T. Komatsu, T. \& Yashima, T. (1997). Isomerisation of $n$-heptane over Pt-loaded zeolite $\beta$ catalysts. Applied Catalysis A; General, 159(1-2): 119-132.

Weitkamp, J., Jacob, P. A. \& Martens, J. A. (1983). Isomerization and hydrocracking of $\mathrm{C}_{9}$ through $\mathrm{C}_{16}$ n-alkanes on $\mathrm{Pt} / \mathrm{HZSM}-5$ zeolite. Applied Catalysis, 8(1):123-141.

Woltz, C., Jentys, A. Lercher, J. A. (2006). Improving bifunctional zeolite catalystsfor alkane hydroisomerization via gas phase sulfation. Journal of Catalysis 237:337-348.

Yashima. T., Wang, Z. B. , Kamo, A., Yoneda, T. \& Komatsu, T. (1996). Isomerisation of n-hexane over Pt loaded zeolite catalysts. Catalysis Today, 29(1-4):279-283.

York, A. P. E., Pham-Huu, C., Gallo, P. D., \& Leudox, M. J. (1997). Molybdenum oxycarbide hydrocarbon isomerisation catalysts: Cleaner fuels for the future. Catalysis Today, 35(1-2):51-57. 